\title{
Private hospitals could turbo-boost public sector reform
}

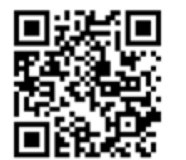

A renowned global authority on national healthcare systems says the South African (SA) government should shift its focus from only supporting public hospitals to leveraging the skills and expertise of their private counterparts to turbo-boost state reform in preparation for a universal healthcare system.

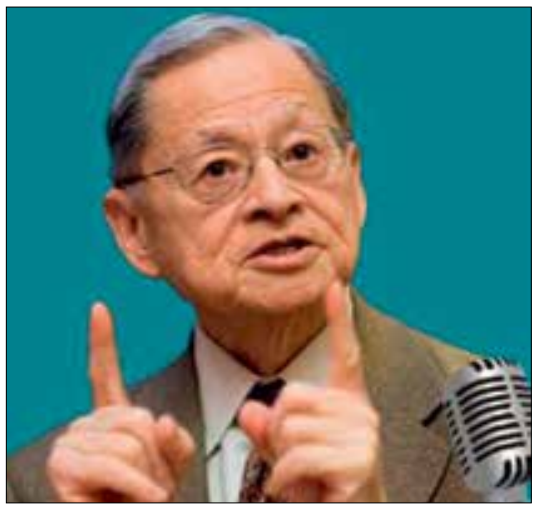

Prof. Bill Hsiao, Harvard University health economist.

Speaking at the Hospital Association of South Africa (HASA) conference on 21 September this year, Prof. Bill Hsiao, a Harvard University health economist who has provided analysis and consulting services to 30 countries in Europe, Africa, Asia and Australasia, said that the longterm goal would be to harmonise the public and private health sectors. Hsiao has served as an advisor to three US presidents, the US Congress, and other global health and economic organisations such as the International Monetary Fund, World Bank and International Labour Organization. He told delegates that until now the government's efforts have been aimed mostly at supporting public hospitals when more short-term solutions could be found by leveraging private hospitals, most of which are HASA members. HASA's members, with 37000 acute hospital beds, 220 hospitals and 150000 employees, could use its knowledge, experience and innovation to help contribute to better quality healthcare, access to treatment and efficiency if the two sectors could find a way to work together.

'In the short run the challenge remains how to leverage the strengths of the private sector to strengthen the healthcare system of SA.'

Giving some pragmatic pointers, Hsiao said that the state could contract hospital management companies to transfer knowledge and operational systems to public hospitals, and that Singapore had done just this. Selected functions such as food and laundry, and the management of public hospitals or administration of social health insurance, could also be outsourced.

'From an international perspective, up to this point, the National Health Insurance pilot system has only tried to strengthen the delivery system in the public sector. There needs to be more active piloting and trying out of alternatives,' said Hsiao.

'I liken the long-term aim of harmonising the healthcare system to an orchestra. One not only needs to include the various sections of an orchestra, to create a whole, but also to teach them how to work together. In this sense, the public and private hospitals have different strengths that need to work together. On the one hand, the public hospitals offer universal access and are publicly funded, while on the other, private hospitals attract private investment and are targeted at those who are willing and able to pay. Public hospitals were far more bureaucratic when compared to the far more agile and dynamic private hospitals that are driven by market forces.

'In this type of environment, private hospitals are driven by competition and have to respond by appealing to what patients want and their willingness to pay as well as to be alert and innovate. This is not always the case with public hospitals.'

'If you unlock people's imagination and technical knowhow, you can develop highly specialised services at much less cost,' he added.

Public hospitals could benefit by using private sector hospital managers and gain the latest international knowledge and experience in managing hospitals. Globally the private sector offered a source of capital investment and services not provided by the public sector, and was a source of knowledge and management skills for social health insurance plans and hospitals and health centres.

'This can be leveraged to the benefit of everyone - if you unlock people's imagination and technical know-how, you can develop highly specialised services at much less cost,' he added.

Dumisani Bomela, Chief Executive of HASA, said that his organisation was committed to ongoing discussions with the Department of Health with a view to strengthening healthcare delivery.

\section{Chris Bateman}

chrisb@hmpg.co.za

S Afr Med J 2015;105(11):890

DOI:10.7196/SAMJ.2015.v105i11.10198 